\title{
Soluble milk constituents
}

\section{By M. PeAker and AnNe Faulkner, Hannah Research Institute, Ayr KA6 ${ }_{5} H L$}

Is the composition of the aqueous phase of milk subject to manipulation? The question is clear and simple but with present knowledge the answer must be divided into three parts. For the major components, which account for most of the osmotic concentration (lactose, potassium, sodium, chloride), the answer is no; for some lesser components, yes to some extent; and for some minor components, yes to a marked extent.

Before describing the basis of the answers to the question, we should point out that they apply to healthy animals under 'normal' conditions of husbandry. We should also point out two factors which have bedevilled the study of milk composition in dairy animals. One is the continued use of terms for milk components which are not representative of single, or even related, chemical entities. There is nothing more annoying and wasteful of research effort than to see milk composition reported solely in such terms as solids-not-fat or ash. There is really no excuse in the 1980 (nor was there in the 1960 and 705 ) for us to accept such analytical nonsense.

The second factor is the incidence of mastitis which, independently of systemic influences, can affect not only the yield of milk but also the concentrations of components of the aqueous phase. Indeed, many of the published values for the composition of cow's milk, as say collected from the farm or bulked in the dairy, are affected to a greater or lesser extent by mastitis. Since milk composition in glands damaged by infection varies, sometimes markedly, from day to day (Linzell \& Peaker, 1972; Linzell et al. 1974), it can not only be very difficult to detect more subtle changes in milk composition against this pathological background but the unwary can be led into believing that since variation is large, manipulation is possible. But in this case manipulation is simply prevention of infection. In healthy glands milk composition is remarkably constant.

It is stating the obvious that changes in composition are achieved by changing the secretory rate of one component relative to that of another, but the fact most often overlooked is that water is a milk component. Failure to recognize this and the difference between secretory rate and concentration of a milk constituent has resulted in misleading studies; for example, attempts have been made to correlate lactose synthetase activity with the concentration of lactose in milk. The activity of lactose synthetase may well be related to the rate of lactose synthesis but the concentration at which that lactose is present in milk need bear no relation to its rate of secretion, since concentration also reflects the rate of secretion of other milk constituents, in this case water and monovalent ions.

The importance of water and ion movements in the formation of the aqueous phase of milk has meant that advances in this field have been based more on 
transport physiology than on biochemistry. The more recent findings that biochemical differences in the gland, some induced by nutritional shifts, are reflected in the concentrations of some of the lesser and minor milk constituents, illustrate that the study of milk secretion is a fertile field for multidisciplinary studies on synthesis, secretion and transport. Indeed, the complexity of milk secretion has recently caused one of us to liken it to a dream-and a nightmare (Peaker, 1982).

\section{Potential plasticity}

In the extremes of manipulation afforded by experimentation in vitro, it is possible to cause shifts in milk composition by altering substrate supply to an extent quite beyond that which can be achieved in vivo. The isolated, perfused goat mammary gland (Hardwick \& Linzell, 1960; Linzell et al. 1972) has been used in demonstrating plasticity in the secretion of some milk constituents relative to others. For example, omission of amino acids from the substrate mixture that was added to the perfusate led to a fall in the output of protein but not of fat or lactose (Hardwick et al. 1961). Similarly, the omission of glucose led to a fall in the output of lactose and water. Then, when endogenous glucose was virtually exhausted and the rate of milk secretion was very low, the concentration of lactose fell while concentrations of the monovalent ions increased (Peaker, 1977a). Except in cases of starvation or insulin-induced hypoglycaemia, when smaller changes occur, such alterations in milk composition caused by gross changes in substrate supply cannot be induced in vivo. Nevertheless, studies on potential plasticity are useful because they do indicate the sort of effect that might be achieved if control of some particular synthetic pathway were to be gained by less severe means.

\section{Components of the aqueous phase}

The major components of the aqueous phase of milk are shown in Fig. I. However, the quantitative contribution to milk does not necessarily reflect the importance of manipulating the concentration of a component from a nutritional or processing-properties point of view (see Muir et al. 1983).

\section{Osmotic constraints}

In all species so far studied bar one, the southern elephant seal Mirounga leonina (Peaker \& Goode, 1978), milk is virtually isosmotic, and probably isotonic, to blood plasma. This is a major constraint on alterations to the aqueous phase and reflects the free permeability of the cell membranes of the secretory and duct cells to water (see Linzell \& Peaker, 1971 $a$; Peaker, 1978). No studies done so far lead one to suspect that the permeability to water is a property that can be altered.

\section{Pathways of secretion and equilibration}

Transcellular mechanisms of secretion and transport are responsible for establishing and maintaining the concentration gradients of the major constituents of the aqueous phase between plasma, intracellular fluid and milk. Possible 

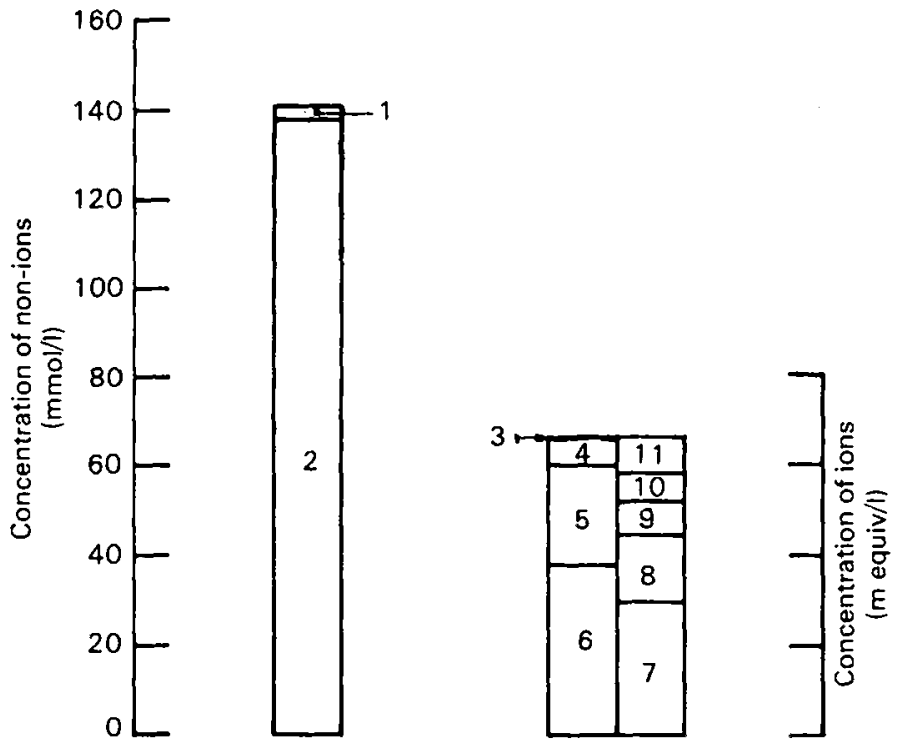

Fig. 1. Concentrations of the main components of the aqueous phase of cow's milk. Non-ions: I, urea; 2, lactose. Ions: 3 , magnesium; 4, calcium; 5, sodium; 6 , potassium; 7 , chloride; 8 , monohydrogen orthophosphate and orthophosphate; 9 , calcium citrate; ro, monohydrogen citrate; 11 , other anions.

mechanisms have been discussed by Linzell \& Peaker (1971 $a$ ) and Peaker (1978) and will not be described further. In general, it is the permeability and transport properties of the Golgi apparatus and its vesicles, and of the apical cell membrane, which are responsible for determining the concentration of substances in milk and for the tight stoichiometry between the mechanisms. Within a species, or more particularly within a breed of dairy animal, it is this stoichiometry in transcellular secretion which is difficult to perturb. In goats and cows there are small variations from day to day and the direction of the shifts is such that if the concentration of lactose falls, those of the major monovalent ions increase (see Peaker, 1978). In the rat similar but larger changes occur during lactation (Chalk \& Bailey, 1979).

In certain conditions a paracellular route exists across the mammary epithelium. In full lactation it would appear that this route is not present in dairy animals, except temporarily, before oestrus for example (see Peaker, 1978). However, the effects of mastitis are due to a paracellular route across the damaged epithelium. The effect of a paracellular route is to allow partial equilibration of small molecules and ions between milk and extracellular fluid. Therefore, the concentrations of sodium, chloride and bicarbonate, for example, in milk increase while those of lactose and potassium fall.

While it is difficult to shift the major composition of the aqueous phase of milk within a species, there are differences between species and breeds (see Peaker, $\mathrm{r} 977 b$ ). Thus, for example, the concentration of lactose is much higher in man and rhinoceros than in dairy animals. However, the important point is that they are 
genetically-determined alterations in composition. Knowledge of the molecular basis for such differences between species would clearly be of interest.

\section{Lesser and minor milk components}

There are many other components in the aqueous phase of milk in addition to the major components already mentioned. They range from steroid and protein hormones, to cytosolic enzymes and intracellular metabolites and their concentrations in milk are generally low. Some are ionized, some are not. To date, no essential function for the sucking animal of these minor components in milk has been demonstrated and it is possible that they 'leak' into milk during the normal secretory processes. Large molecules, such as cytosolic enzymes, are probably secreted into milk along with the tiny drops of cytoplasm which are trapped inside the milk fat globule membrane during the secretion of milk fat. Smaller molecules, such as the intracellular metabolites, may cross the Golgi membrane (e.g. UDPgalactose) and can then be secreted into milk along with lactose or may permeate the apical cell membrane (e.g. glucose) and enter milk directly from the cytosol of the mammary epithelial cell. Whatever their mode of transport, the concentrations of these minor components in milk can vary considerably and, although they may have no nutritional or commercial importance, their concentrations in milk may be useful indicators of the general physiological state and mammary metabolism of the lactating animal.

Both protein and steroid hormones are present in milk. The protein hormones are generally present at lower concentrations in milk than in plasma but the steroid hormones may be present at higher concentrations. In both cases the changes in the concentrations of the hormone in milk vary directly with those occurring in the plasma. Thus it may be possible to determine the hormonal status of a lactating animal by milk analysis rather than by blood sampling and analysis. Already the presence of progesterone and oestrogens in milk is being utilized in pregnancy testing of dairy cows. At $21 \mathrm{~d}$ after insemination, the progesterone level in pregnant animals is about double that of the non-pregnant animals, providing a basis for pregnancy testing (Heap et al. 1976). The determination of oestrone sulphate levels in milk later in pregnancy ( $100 \mathrm{~d}$ ) may also be useful in providing confirmation of pregnancy in cows diagnosed previously to be pregnant by the milk progesterone test (Hamon et al. I98I).

Hormones are not only components the concentrations of which in milk vary with those in plasma. The concentrations of ketone bodies behave in a similar way and, hence, the onset of ketosis may be diagnosed by analysis of milk samples for ketone bodies (Schultz \& Myers, 1959).

The concentrations of some other minor components in milk appear to vary with intracellular or Golgi vesicular concentrations within the mammary epithelial cell rather than with plasma concentrations. Glucose, for example, appears to equilibrate across the apical membrane of the secretory cell; thus milk glucose levels may reflect intracellular concentrations (Kuhn \& White, 1975) and hence the availability of glucose for lactose synthesis in the mammary gland. In support of 
this theory, changes in milk glucose concentrations have been shown to be closely correlated with changes in the rate of lactose synthesis and milk secretion (Faulkner et al. 198I). Other metabolites which are present in milk, such as acetate, may also cross the apical membrane and their concentrations in milk may provide further information on mammary metabolism and substrate supply.

Recent work has involved studies of the concentrations of isocitrate and 2oxoglutarate in cow's and goat's milk. These organic acids are components in the reaction catalyzed by isocitrate dehydrogenase which is the main pathway for the generation of reducing power (NADPH) for mammary fat synthesis (Chaiyabutr et al. 1980). The ratio of the concentrations of these organic acids in milk correlates with the rate of fatty acid synthesis in the mammary gland (Chaiyabutr et al. 1981; Faulkner \& Clapperton, 198I) and this ratio appears to be a good indicator of mammary fat synthesis and possibly also of the availability of lipid for mammary metabolism.

Therefore, changes in the concentrations of some of the minor components of milk may be valuable diagnostic tools, although they may have no nutritional or commercial importance. However, changes in the concentrations of citrate and urea in milk may be of commercial significance as their concentrations can affect the processing characteristics of milk (Muir \& Sweetsur, 1976, 1977; Holt et al. I980). Hence it is important not only to understand the causes of their variations in concentration but also to be able to manipulate them. The extent to which the levels of citrate and urea can vary in milk is demonstrated by the changes which occur during short-term $(48 \mathrm{~h})$ starvation in the goat: milk urea and citrate concentrations increase more than two-fold.

Citrate is secreted into milk along with lactose via the Golgi vesicles (Linzell et al. 1976; Zulak et al. 1978). Its concentration in milk can vary considerably with changes in nutrition (Ormrod et al. 1979, 1980), stage of lactation (Konar et al. I97I; Peaker et al. 198I) and season (Holt et al. 1978; Mitchell, 1979). In some cases the changes in milk citrate levels appear to be inversely related to the rate of fat synthesis in the mammary gland, and we (Faulkner \& Peaker, 1982) have proposed that changes in milk citrate levels reflect changes in intracellular citrate concentrations. Citrate and isocitrate are maintained in equilibrium in the cell so that changes in the rate of utilization of isocitrate will affect citrate concentrations. Isocitrate is the substrate for the isocitrate dehydrogenase reaction which is a major pathway for NADPH synthesis necessary for fat synthesis in ruminants (Bauman \& Davis, 1974). Thus, one way in which the citrate content of milk may be manipulated is by changing the rate of fat synthesis in the mammary gland, high rates of mammary fat synthesis producing milk with a low citrate content and vice versa. The concentration of citrate has a major effect on the distribution of calcium in milk.

Variations in the urea content of milk have been reported and may be related to feed supply, e.g. urea concentration in milk increases with the nitrate content of the feed (Bielak, 1978) and increases are observed after the change from winter feeding to spring pasture (Vignon et al. 1978). It has been suggested that 
the urea content of milk is related to the net excess of dietary protein supplied (Erbersdohler et al. 1980). Urea in milk may be derived from plasma or from the metabolism of arginine in the mammary gland (Graham et al. 1937; Mepham \& Linzell, 1967). The concentrations of urea in milk and plasma are similar since the mammary epithelium is highly permeable to urea (Linzell \& Peaker, 1971 $b$ ) but it is likely that a major portion of milk urea is derived from the metabolism of arginine. This amino acid is taken up in quantities well in excess of the requirement for protein synthesis (Mepham \& Linzell, I966; Bickerstaffe et al. 1974) and excess arginine is metabolized to form other amino acids with the simultaneous production of urea (Mepham \& Linzell, 1967; Yip \& Knox, 1972). Thus it may prove possible to manipulate the urea content of milk to some extent by controlling the supply and metabolism of amino acids, especially arginine, in the mammary gland.

\section{Conclusions}

It must be admitted that the prospect for manipulating the composition of the aqueous phase of milk in terms of its major components is not bright, other than by the slow process of genetic selection. This is not the case with some other constituents which affect processing characteristics, as exemplified by citrate; in this case manipulation of the citrate-calcium complex is possible. Finally, there is a group of minor components which vary in concentration markedly with physiological state and which may be used as diagnostic aids for events in the whole animal and in the mammary gland, including manipulative processes.

\section{REFERENCES}

Bauman, D. E. \& Davis, C. L. (1974). In Lactation: A Comprehensive Treatise, vol. 2, p. 31 [B. L. Larson and V. R. Smith, editors]. London: Academic Press.

Bickerstaffe, R., Annison, E. F. \& Linzell, J. L. (1974). F. agric. Sci., Camb. 82, 71 .

Bielak, F. (1978). Dairy Sci. Abstr. 40, 539.

Chaiyabutr, N., Faulkner, A. \& Peaker, M. (1980). Biochem. f. 186, 301.

Chaiyabutr, N., Faulkner, A. \& Peaker, M. (198r). Br. F. Nutr. 45, 149.

Chalk, P. A. \& Bailey, E. (1979). Comp. Biochem. Physiol. 63A, 6 rg.

Davies, D. T. \& White, J. C. D. (I 960). F. Dairy Res. 27, 171 .

Erbersdohler, H. F., Eckart, K. \& Zucker, H. (I 980). Landw. Forsch. Sonderheft 36, 98.

Faulkner, A., Chaiyabutr, N., Peaker, M., Carrick, D. T. \& Kuhn, N. J. (rg8r). F. Dairy Res. 48, 5 i.

Faulkner, A. \& Clapperton, J. L. (1981). Comp. Biochem. Physiol. 68A, 281.

Faulkner, A. \& Peaker, M. (1982). fु. Dairy Res. 49, 159.

Graham, W. R., Houchin, O. 13. \& Turner, C. W. (1937). Y. biol. Chem. 120, 29.

Hamon, M., Fleet, I. R., Holdsworth, R. J. \& Heap, R. B. (1981). Br. vet. F. 137, 71.

Hardwick, D. C. \& Linzell, J. L. (1960). F. Physiol., Lond. 154, 547.

Hardwick, D. C., Linzell, J. L. \& Price, S. M. (1961). Biochem. F. 80, 37.

Heap, R. B., Holdsworth, R. J., Gadsby, J. E., Laing, J. A. \& Walters, D. E. (1976). Br. vet. F. 132, 445 .

Holt, C., Muir, D. D., Ormrad, I. H. L., Zammit, V. A. \& Peaker, M. (1980). Hannah Res. Inst. Rep. 1979, p. 63.

Holt, C., Muir, D. D. \& Sweetsur, A. W. M. (1978). F. Dairy Res. 45, 183. 
Konar, A., Thomas, P. C. \& Rook, J. A. F. (1971). F. Dairy Res. 38, 333.

Kuhn, N. J. \& White, A. (1975). Biochem. F. 152, 153.

Linzell, J. L., Fleet, I. R., Mepham, T. B. \& Peaker, M. (1972). Q. fl. exp. Physiol. 57, 139.

Linzell, J. L., Mepham, T. B. \& Peaker, M. (r976). F. Physiol., Lond. 260, 739.

Linzell, J. L. \& Peaker, M. (197ra). Physiol. Rev. 5 I, 564.

Linzell, J. L. \& Peaker, M. (1971 b). F. Physiol., Lond. 216, 701.

Linzell, J. L. \& Peaker, M. (1972). Br. vet. $\mathcal{F}$. 128, 284.

Linzell, J. L., Peaker, M. \& Rowell, J. G. (1974). F. agric. Sci., Camb. 83, 309.

Mepham, T. B. \& Linzell, J. L. (1966). Biochem. F. 101, 76.

Mepham, T. B. \& Linzell, J. L. (1967). Nature 214, 507.

Mitchell, G. E. (1979). Aust. F. Dairy Technol. 34, 158.

Muir, D. D., Banks, J. M., Powell, A. K. \& Sweetsur, A. W. M. (1983). Proc. Nutr. Soc. 42, 385 .

Muir, D. D. \& Sweetsur, A. W. M. (1976). F. Dairy Res. 43, 495.

Muir, D. D. \& Sweetsur, A. W. M. (I977). F. Dairy Res. 44, 249.

Ormrod, I. H. L., Thomas, P. C. \& Wheelock, J. V. (1979). Proc. Nutr. Soc. 38, 12 IA.

Ormrod, I. H. L., Thomas, P. C. \& Wheelock, J. V. (I980). Proc. Nutr. Soc. 39, 33A.

Peaker, M. (1977a). F. Physiol., Lond. 270, 489.

Peaker, M. (1977b). Symp. zool. Soc., Lond. 4I, I I 3 .

Peaker, M. (1978). In Lactation, vol. 4, p. 437 [B. L. Larson, editor]. New York: Academic Press.

Peaker, M. (1982). In Functional Regulation at the Cellular and Molecular Levels, p. 245 [R. A. Corradino, editor]. New York: Elsevier North Holland.

Peaker, M., Faulkner, A. \& Blatchford, D. R. (1981). F. Dairy Res. 48, 357.

Peaker, M. \& Goode, J. A. (1978). F. Zool., Lond. 185, 469 .

Schultz, L. H. \& Myers, M. (1959). F. Dairy Sci. 42, 705 .

Vignon, B., Laurent, F. \& Journet, M. (1978). Anals Zootechnie 27, 303.

Yip, M. C. M. \& Knox, W. E. (1972). Biochem. Y. 127, 893.

Zulak, I. M., Eigel, W. N. \& Keenan, T. W. (1978). F. Dairy Sci. 61, (Suppl. 1), 167. 